\title{
Catalase polymorphism May Influence the Pathogenesis of Diabetes Mellitus
}

\author{
Annwyne Houldsworth ${ }^{1 *}$, Andrea Hodgkinson ${ }^{1}$, Andy Demaine ${ }^{1}$, Ann Millward ${ }^{1}$
}

${ }^{1}$ School of Health Professions, Peninsula Allied Health Centre, PL6 8BU.

Received: November 05,2016;Accepted: November 20,2016; Published: December 20,2016

*Corresponding author: Dr Annwyne Houldsworth BSc, MSc, PhD, PGCME, MRSC, FHEA, School of Health Professions, Peninsula Allied Health Centre, PL6 8BU. Abbey Leat, Milton Combe, Yelverton, Devon, PL20 6HP, Tel:+00441822 854322;E-mail: annwyne.houldsworth@gmail.ac.uk.

\begin{abstract}
Diabetes is a heterogeneous disease where many factors are involved in its pathogenesis. The genotype frequency of Catalase (CAT) microsatellite polymorphism in patients with Type 1-Diabetes (T1DM) was analysed. 86 T1DM patients (37M: 49F) and 81 normal controls (43M: $38 \mathrm{~F}$ ) were included in the investigation.

The diabetic controls (DC) had an average age of 34.0 years \pm 2.84 $\operatorname{SEM}(n=7,3 M: 4 F)$, a mean duration of disease of 27.9 years \pm 2.46 SEM and did not have any diabetic complications for at least 20 years. Patients with diabetic nephropathy $(n=16,7 M$ : $9 F)$ were on average 47.3 years \pm 5.54 SEM and had been diagnosed for 30.8 years \pm 2.94 SEM. There was also a group of patients that had been diagnosed for a short duration (SD) with a mean age of 21.7 years \pm 2.60 SEM $(\mathrm{n}=8,5 \mathrm{M}: 3 \mathrm{~F})$. A further 55 patients $(21 \mathrm{M}: 24 \mathrm{~F})$ had been diagnosed for 18.4 years \pm 1.30 SEM; mean age of 26.7 years \pm 1.13 SEM but no complications were recorded and not eligible to be included in the DC group being diagnosed for less than 20 years.
\end{abstract}

Significant differences reported between patients with diabetes ( $\mathrm{n}=86,37 \mathrm{M}: 49 \mathrm{~F})$ and normal healthy controls $(\mathrm{n}=81,43 \mathrm{M}: 38 \mathrm{~F})$. Patients with diabetes had a higher percentage of heterozygous copies (54\%; Chi-square $=5.87 ; p=0.01)$; normal controls had a higher homozygous percentage $(63 \%$; Chi-square $=6.5 ; \mathrm{p}=0.01)$.

\section{Conclusion}

This is the first reported polymorphism of CAT that may be associated with the cellular damage causing the onset of diabetes

Keywords:Diabetes; CAT; Oxidative Stress; Hydrogen Peroxide; Genotype; Microsatellite; Pathogenesis; Amyloids; Pancreata

\section{Abbreviations}

CAT: Catalase; T1DM: type 1 diabetes mellitus; T2DM: type 2 diabetes mellitus; Th1: $\mathrm{T}$ helper 1 cell; microsatellite polymorphism; SNP: single nucleotide polymorphism; ROS: reactive oxygen species; OS: oxidative stress; DN: diabetic nephropathy; WHO: World Health Organisation.

\section{Introduction}

The global prevalence of diabetes is about $9 \%$ in adults over eighteen years [1]. The exact cause of Type 1 Diabetes Mellitus (T1DM) is not known, nor is it preventable with current knowledge, but it can be treated with daily administration of insulin. Patients with this heterogeneous, multi factorial and polygenic disease are at increased risk of diabetic complications due to impaired blood flow with micro vascular complications, such as, retinopathy, neuropathy and nephropathy, and macro vascular complications, including cardiovascular, peripheral vascular disease and cerebro vascular diseases. This investigation primarily concerns patients with T1DM. However, although T1DM and T2DM are usually considered quite separately, there are some similarities between the two conditions, both of these conditions will be considered in building this picture of antioxidant responses to oxidative stress in the pathogenesis of diabetes [2,3]. Increasingly, T2DM is recognised as a proinflammatory state with an increased risk of macro and micro vascular disorders, due to oxidative stress. Increased oxidative stress is manifested by increased lipid peroxidation and in increased DNA damage [4,5], whereas T1DM manifests itself as an attack of autoreavtive T-cells against pancreatic beta cells but in many ways the two conditions overlap substantially with both resulting in the deterioration of glycaemic control [6].

Patients with diabetes often suffer from cardiomyopathy, which cannot be explained by impaired cardio perfusion. Cardiovascular disease risk is two- to four-times greater in individuals with Type 2 Diabetes Mellitus (T2DM), relative to individuals without diabetes. Further, diabetes is accompanied by increased cellular inflammation, as evidenced by increased monocytic superoxide, cytokines and adhesion to endothelium [5].

The essential beta cell dysfunction can be influenced by many factors, including hyperglycemia/glucotoxicity, lipotoxicity, autoimmunity, inflammation, adipokines, islet amyloid, incretins and insulin resistance that can all influence the function of pancreatic beta cells. The resulting hyperglycaemia induces an excessive production of reactive oxygen species (ROS) leading to chronic oxidative stress (OS) [7]. Studies on islets isolated from pancreata of subjects with T2DM showed increased markers of 
oxidative stress and these correlated with the degree of glucosestimulated insulin secretion impairment [8]. Indeed, metabolic abnormalities associated with diabetes cause an overproduction of superoxide radicals in the mitochondria in large and small vessel endothelial cells [9].

Catalases are ubiquitous enzymes that are extremely efficient in preventing a cell from oxidative injury. Catalase (CAT) decomposes hydrogen peroxide formed by SOD-2 and flavinlinked oxidases and can be found within peroxisomes in the microbodies found in animal cells.

The activity of CAT has been observed in nearly all animal cells and organs as well as aerobic micro-organisms[10].In erythrocytes, CAT with glutathione peroxidase together exerts, a protective function for haemoglobin and enzyme, membrane and stroma proteins [11].

Although oxygen is essential for human respiration within cells [12], cells are highly vulnerable to the effects of oxidation and also lie at the root of non-human, obligate anaerobiosis and the spontaneous associated mutagenesis. Interestingly, unlike eukaryotes, obligate anaerobes produce very little or no CAT and are killed in relatively low concentrations of oxygen [13].

Molecular oxygen has two unpaired electrons in its outer orbital and can be readily reduced to superoxide and hydrogen peroxide within cells but aerobic organisms produce Super Oxide Dismutase-2 (SOD-2) and CAT to detoxify these free radicals [14].

Although hydrogen peroxide is a weak oxidising agent and is not a free radical, it is usually included in the general title of ROS. Unlike the superoxide ion, it can cross cell membrane boundaries and decomposes to form the reactive hydroxyl radical [15]. CAT destroys hydrogen peroxide in two steps, using a haem group in its structure. Each of the two steps involves the transfer of an electron rather than the one step, two-electron transfer reported in earlier literature [16]. CAT first binds to a hydrogen peroxide molecule and then splits the molecule resulting in an oxygen atom binding to the iron atom in the haem group and the other oxygen atom being extracted; the rest is released as water. After this a second hydrogen peroxide molecule binds to CAT and is similarly broken apart, it combines with the previously iron-bound oxygen atom, thus releasing water and oxygen gas [17].

It has recently been observed that, at low concentrations, hydrogen peroxide acts as a cellular messenger in insulin signaling, whereas at high concentrations it is toxic, particularly in pancreatic cells, which are catalase poor. Erythrocyte catalase is the main regulator of hydrogen peroxide metabolism; any inherited or acquired deficiencies in erythrocyte catalase may cause increased hydrogen peroxide concentrations with both toxic and physiological effects.

Acatelasia is an inherited deficiency of the catalase enzyme and Hungarian acatalasemic patients with an increased frequency of T2DM, especially in female patients and had an early onset of T2DM was observed in these patients [18].

The structure of tetrameric haemin-enzyme, CAT, consists of four identical tetrahedrally arranged sub-units each containing 4 ferriprotoporphyrin groups per molecule [19].

Although the detailed mechanisms vary considerably, CAT gene expression in microorganisms generally is controlled, either by sensors of ROS or by growth phase regulons. There is a surprisingly wide range of catalytic efficiencies, despite the similar sequences being found in the enzyme. Biomedical and physiological characterization of cats have revealed many roles in many different organisms [20].

Antioxidant responses to hyperglycemia have shown that, although SOD-2 responses did not change between diabetic patient complication groups or in normal controls, there was, however, a twofold increase in the expression of CAT under hyperglycemic conditions suggesting that high glucose flux through aldose reeducates inhibits the expression of antioxidant enzymes [21]. Polymorphic differences with functional impairment of the mnsod gene are associated with an increased risk of diabetic nephropathy and that the $\mathrm{V}$ allele of the SOD2 rs4880 polymorphism (SNP) increases the risk of diabetic nephropathy in patients with T1DM [22].

A microsatellite polymorphism (D11S2008) of the CAT gene region has been identified, closely linked to the CAT gene on chromosome 11p13, including a CTAT repeat array $[23,24]$.

CAT

$$
2 \mathrm{H} 2 \mathrm{O} 2 \rightarrow 2 \mathrm{H} 2 \mathrm{O}+\mathrm{O} 2
$$

B) $\mathrm{ROOH}+\mathrm{AH} 2 \rightarrow \mathrm{H} 2 \mathrm{O} 2+\mathrm{ROH}+\mathrm{A}$

The microsatellite polymorphism studied in the patients with T1DM from the D11S2008 CAT gene region has been weakly associated with coronary heart disease and blood pressure levels in patients with T2DM [23].

As this region is considered to be important in eliminating oxidative stress in the individuals studied, we have considered it as a possible polymorphic ally relevant site for our study of Th1 inflammatory responses.

The CAT polymorphism studied is proximal to and closely linked with the CAT gene on, chromosome $11 \mathrm{p} 13$, including the CTAT repeat array. Polyacrylamide gel electrophoresis was performed for microsatellite analysis using an 8\% gel concentration and the reverse primer was radio labelled with ${ }^{32 p}$ ATP [25].

\section{Methods \\ Patient cohort}

Diabetic Patient Complications: Nephropathy (DN) was described in patients with more than 10years of diabetes and Proteinuria at least $3 \mathrm{X}$ in 12 months. Retinopathy (DR) was defined in patients with more than 5 dots or blots per eye, hard or soft exudates, new vessels evidence of maculopathy or vitreous haemorrhage. Short Duration (SD) patients had been diagnosed with diabetes for less than 10 years whereas uncomplicated (DC) 
patients displayed no complications after 20-year duration of T1DM.

Controls: 135 ethnically matched controls were studied. Control DNA was obtained from the cord blood of European Caucasoid subjects collected sequentially after normal obstetric delivery from the Obstetric Department, Derriford Hospital (Plymouth, UK).

Ethics committee approval and patient consent was obtained for all studies performed.

CAT genotype for patients with T1DM: The 86 patients with T1DM (37M: 49F) included in this study had a mean age of 19.3 years \pm 1.43 SEM. These were compared with 81 normal controls (43M: $38 \mathrm{~F}$ ). The medical history of the patients was recorded but not included in the genetic comparisons as there were insufficient numbers in each group. Diabetic controls (DC) had an average age of 34.0 years \pm 2.84 SEM ( $n=7,3 \mathrm{M}$ : $4 \mathrm{~F}$ ), a mean duration of disease of 27.9 years \pm 2.46 SEM and did not have any diabetic complications for at least 20 years. Patients with nephropathy $(n=16,7 \mathrm{M}$ : 9F) were on average 47.3 years \pm 5.54 SEM and had been diagnosed for 30.8 years \pm 2.94 SEM. There was also a group of patients that had been diagnosed for a short duration (SD) with a mean age of 21.7 years $\pm 2.60 \mathrm{SEM}(\mathrm{n}=8,5 \mathrm{M}$ : $3 \mathrm{~F}$ ). A further 55 patients (21M:24F) had been diagnosed for 18.4 years \pm 1.30 SEM with a mean age of 26.7 years \pm 1.13 SEM but there were no complications recorded and they were not eligible to be included in the DC group being diagnosed for less than 20 years (table 1).

This is a retrospective study of DNA samples collected from patients visiting a diabetes clinic after diagnosis thus no other blood results such as hba1c, lipids, insulin, glucose were not available. DNA was collected for the control group, taken from cord bloods from Derriford Hospital maternity unit.

Genetic studies: Genomic DNA was extracted conventionally from whole blood using a 'salting out' method. The restriction site was found at -9 on the mitochondrial targeting sequence of the manganese superoxide dismutase, which is a $\mathrm{C}$ to $\mathrm{T}$ substitution resulting in an amino acid change of alanine to valine.

The CAT polymorphism studied is proximal to and closely linked with the CAT gene on chromosome $11 \mathrm{p} 13$ including the CTAT repeat array. Polyacrylamide gel electrophoresis was performed for microsatellite analysis using an 8\% gel concentration and the reverse primer was radio labelled with ${ }^{32 \mathrm{p}}$ ATP [36].

Polymorphism of D11S2008 Locus of the CAT Gene Region: Found proximally to and is closely linked to the CAT gene on chromosome $11 \mathrm{p} 13$ including the CTAT repeat array. There is considerable evidence that this locus is in linkage with T1DM (11p15) [26].

PAGE was performed for microsatellite analysis using an $8 \%$ gel concentration and the reverse primer was radio labeled with ${ }^{32 p}$ atp [25]. Each run of samples took several days to complete the analysis of the DNA.
Microsatellite analysis: Microsatellites consist of repetitive sequences located in satellite DNA, predominantly found in heterochromatic DNA at chromosomal telomeres and centromeres and orbits the main DNA [27]. They are tandemly repeated arrays of up to six nucleotides.

Microinsertion Polymorphism: Some allelic differences are due to the insertion or deletion of 2, 3 or $4 \mathrm{bp}$ resulting in alleles of differing lengths. These differences can be detected and scored by radio labeling the fragments during amplification with PCR and running Polyacrylamide Gel Electrophoresis (PAGE) and autoradiography.

Autoradiography: Autoradiography imposes a permanent image of the distribution of radioactive atoms on a twodimensional surface on photographic film, which is used to visualize the bands of nucleic acids of varying lengths. ${ }^{32} \mathrm{P}$ emits a particle that is able to penetrate water or plastic to a depth of $6 \mathrm{~mm}$ and can pass completely through X-ray film. Radioactive particles that pass through the film emit photons that are captured by silver halide crystals. ${ }^{32} \mathrm{P}$ Radio labeled primers were hybridized to the sample to be visualized and run through an acrylamide gel using electrophoresis.

5'End Labelling of Oligonucleotide Primers:The use of radioisotopes provides methods that can track and detect nucleic acids. T4 Polynucleotide Kinase (PNK) was used to incorporate ${ }^{32} \mathrm{P}$ from $\left[{ }^{32} \mathrm{P}\right]$ ATP to the 5 ' ends of oligonucleotides.

Reagents: Ready to go T4 Polynucleotide Kinase (Amersham Pharmica Biotech)

$\left[{ }^{32} \mathrm{P}\right]$ ATP (Amersham Pharmica Biotech)

Oligonucleotides- primers (Invitrogen, MWG)

Quick precip

$5 \mathrm{M}$ nacl (Sigma)

Absolute ethanol (Sigma)

$70 \%$ ethanol

Protocol: The ready to go T4 PNK tubes were reconstituted with 25 ls of sterile water. The tube was incubated at room temperature for about 5 minutes and then mixed by gently pipetting up and down. 5 ls of primers at a concentration of $10 \mathrm{pmol} / \mathrm{l}$ were added to the tube followed by 19 ls of sterile water. $1 \mathrm{l}$ of $\left[{ }^{32} \mathrm{P}\right]$ ATP was added and the mixture was vortexed and spun for 30 seconds. The tube was then placed in a water bath at a temperature of $37^{\circ} \mathrm{C}$ for 30 minutes.

5.5 ls of $5 \mathrm{M}$ nacl was added with 2 ls of Quick Precip and 165 ls of $100 \%$ ice-cold ethanol. The mixture was vortexed and centrifuged for 3 minutes at a speed of 13,000g.

Following centrifugation the mixture was vortexed again before further centrifugation for 30 seconds. The supernatant was discarded and 165 ls of $70 \%$ ethanol was added and then centrifuged for 30 seconds. The supernatant was discarded and the tube containing the pellet was left on the bench for about 5 minutes to allow any residual ethanol to be evaporated. The pellet was then reconstituted with 50 ls of sterile water. 
The procedure was repeated using a 30-300bp ladder instead of the oligonucleotide.

A BIORAD sequi-gen GT electrophoresis system (BIORAD Laboratories, Hempstead UK) was used to perform polyacrylamide gel electrophoresis.

The glass sheet and the inner surface of the back plate were cleaned thoroughly with a detergent solution followed by polishing with Methylated spirits. Repel saline was applied to the plates to siliconise the surface and allowed to dry for at least 10 minutes.

The plastic spacers were fitted to the sides of the plates and sealed with Vaseline. The gel cast was assembled and the sequasel products were combined with TEMED and APS then injected into the cast. The shark tooth combs were positioned in the gel in order to form loading wells in the set gel. The ends of the gel were sealed with Saran wrap and allowed to polymerize for at least one hour at room temperature.

The gel rig was filled with 1\% TBE buffer and a current was applied to the gel rig via a power pack with a current of 1600 2000 volts, maintained at a temperature of $50^{\circ} \mathrm{C}$. Six ls of radio labeled DNA were mixed with 3 ls of stop solution and loaded into the wells in the gel. A 30-300bp radio labeled ladder was loaded at the end of each comb.

The electrophoresis time was from 4-6 hours depending on the length of the DNA fragments.

The gel was transferred to $3 \mathrm{MM}$ filter paper, covered with Saran wrap and then dried on a flat bed dryer at $70^{\circ} \mathrm{C}$. The dried gel was placed inside a Cronex cassette with X-ray film in the dark room. The gel was auto radio graphed by being left in the cassette at $-80^{\circ} \mathrm{C}$ for $18-24$ hours depending on the strength of the radioactive signal.

The film was first immersed in the X-ray developer, then the stop bath solution and finally the film developed in a liquid fixer.

The resultant signals on the developed film were compared with a 30-300bp ladder and scored for genotype.

\section{Results}

A significant difference was observed between patients and normal controls. Diabetic patients had a higher percentage of heterozygous copies (54\%; Chi-square=5.87; $\mathrm{p}=0.01$ ) whereas normal controls had a higher homozygous percentage (63\%; Chi-square $=6.5 ; \mathrm{p}=0.01$ ) (table 2). Although any complications were recorded in taking the medical history of the patient, this was not considered in the statistical comparisons of the patient genotypes (table 1).

\section{Power calculation}

A power calculation was performed to ensure that the optimum sample size of patients was recruited for the study to find significant statistical difference in this cohort and the optimum number of normal non-pregnant healthy controls was also determined by the university's medical statistician, however it is understood that optimum sample size may not always be achievable with a this kind of retrospective study, the statistician felt confident that our numbers provided sufficient power to be confident in our comparisons.

In order to ensure that differences between the patient groups were not found by chance, a Bonferroni calculation was applied to the data [27].

\section{Hardy-Weinberg distribution}

In a non-selected population, the relative frequencies of different alleles tend to be constant and are described by a single equation. Several factors may distort the gene frequencies in a population. A high frequency may indicate the possibility that evolutionary forces are in operation and applying selective pressure in favour of heterozygotes or homozygotes for mutant genes that cause the more common inherited disorders. $\left(\mathrm{p}^{2}+2 \mathrm{pq}+\right.$ $\left.\mathrm{q}^{2}=1\right)$

The frequency of the alleles and genotypes in patient and control groups were compared for significance, using contingency tables and chi-squared test with Yates correction where appropriate. $\mathrm{P}$ values of $<0.05$ were considered to be significant. We also included odds ratios with $95 \%$ confidence limits where appropriate.

\section{Discussion}

In this investigation, the comparison was only made between patients with diabetes and those without as there were fifteen possible combinations of allelic combinations in the microsatellite investigated thus a much larger group of patients would be required to identify significant differences between the many patient complication groups. The sample size was considered to be adequate to compare these two groups after consultation with a statistician, who performed the power calculation.

It must be noted that previous studies did not find an association with CAT and T1DM [28, 29]. CAT has been shown to be associated with several other disease conditions. In animal cells decreased CAT levels were observed in breast cancer, adenomas and leukemia [30].This is the first study to demonstrate a genetic difference in this CAT polymorphism and T1DM.

The intracellular beta cell ion environment can be destabilized by the generation of ROS so disrupting the normal insulin secretory kinetics. There is convincing evidence for the role of oxidative stress in human disease pathogenesis. The presence of amyloids in beta cells, causing cellular damage, is the partly the result of aberrant protein folding in this hostile environment of ROS [31, 32, 33]. Aberrant protein folding can be influenced by $\mathrm{PH}$, which is influenced by the presence of ROS. Enzyme activity is also influenced by the $\mathrm{PH}$, temperature, salts content, activators and inhibitors [34].

Although oxygen derivatives are the most important free radicals in many disease states, particularly superoxide and the hydroxyl radical, hydrogen peroxide also plays a role in oxidative damage and CAT is an important protective factor against this [35]. 
The over-expression of CAT has been shown to preserve normal cardiac morphology. CAT over expression protected cardiomyocyte contractility in the agouti model of T2DMand showed that both T1 and T2DM induce damage at the level of individual myocytes, when this damage occurs through mechanisms utilizing ROS[36]. Beta cells are damaged by oxidative stress as it activates stress induced pathways, resulting in defective insulin biosynthesis and secretion thus the different expressions of antioxidant genes, such as CAT, could influence this damage process, where homozygote CAT genes may be more effective in reducing the pathogenesis of diabetes [37].

It was found that the heterozygote groups were more significantly likely to be patients diagnosed with diabetes than the homozygous group. The CAT antioxidant efficiency of the homozygote group may be more enhanced that the heterozygote group. The physiological function of bimolecular and their integrity is impaired by ROS accumulation. The susceptibility to this stress, that can impair the cells function and viability, can be determined by their ability to repair the damage to DNA, made by the oxidative stress [38]. The defense mechanism that CAT provides may be affected by its genotype (ie. CAT heterozygote's are more susceptible) thus revealing a particular phenotype that is more likely to develop diabetes (diagram 1).

Microsatellite DNA is in the untranslated region of the gene but has increasingly been associated with protein translation and expression. They can also regulate or change gene products and can eventually lead to phenotype changes [39].

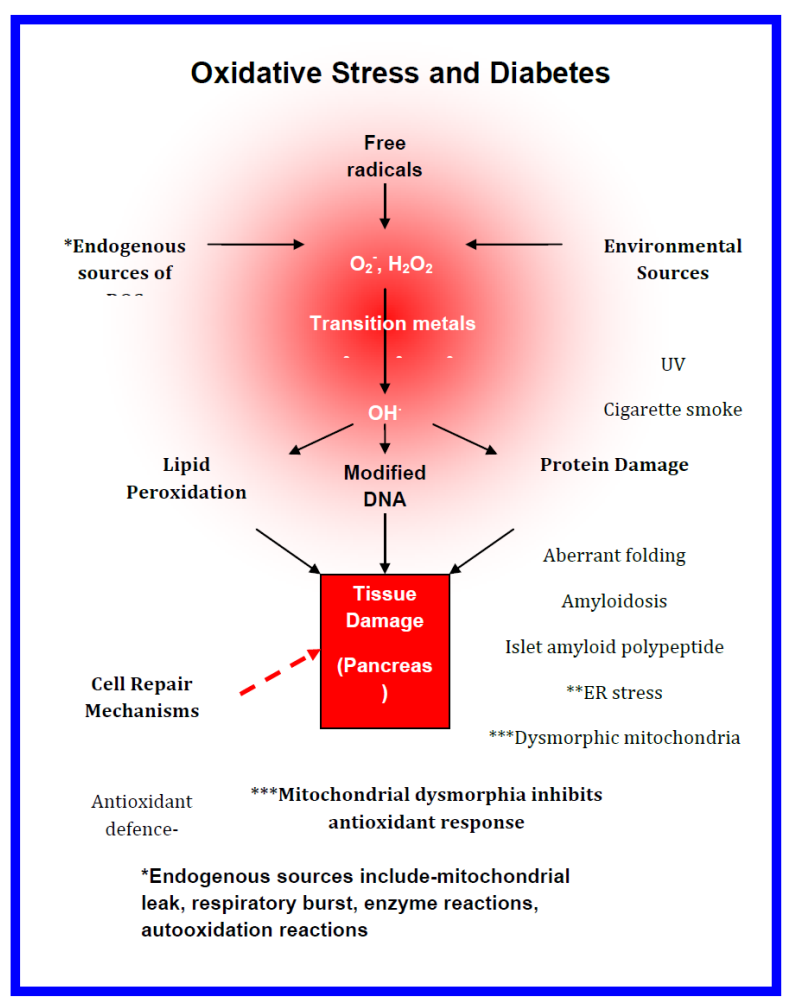

Figure 1
It is known that the epistasis of an allele of one gene affects the expression of another and that the phenotype may be altered by the combination of different alleles. A trait is determined by dominance and is a relationship between alleles. An allele can be dominant for only one aspect of the allele's expression, co-ordinate with another allele and recessive with another [40]. Whereas, there are different forms of some traits and an allele of one gene may affect the expression of another allele, even at a different gene at heterozygous gene loci. The two alleles can interact to produce the phenotype [41]. In the case of the polymorphism, which was investigated in this study, the different alleles may have interacted in such a way as to reduce CAT expression or effectiveness. This hypothesis requires much further investigation with the new recruitment of patients with diabetes and catalase expression studies performed. This was not possible with our cohort as we were analyzing retrospective DNA samples.

It has been reported that CAT expression increased by twofold under hyperglycaemic conditions, suggesting that high glucose flux requires greater CAT expression [21]. Thus an allelic combination that may infer a less effective gene expression of CAT, under oxidative stress and induced by hyperglycaemia, may be expected in patients with diabetes mellitus. The relative expression of all fifteen different allelic combinations may be required to clarify this further. It may be that our results indicate that all diabetic complications are similarly affected by the heterozygote phenomenon.

This is the first example of a catalase polymorphism being associated in patients with diabetes compared to normal controls. Recently, human retinal Müller and pigment epithelial cells were chronically exposed to normal or high glucose levels and treated with a cell-penetrating derivative of the peroxisomal enzyme CAT, called CAT-SKL, to reduce oxidative stress with some success at reducing the pathophysiology associated with ROS in retinal cells. CAT-SKL is a cell-penetrating, peroxisome-targeted, protein biologic and is a genetically engineered recombinant derivative of CAT containing a cell penetrating peptide at its amino terminus and an altered, more efficient peroxisomal targeting signal at its carboxy terminus [42]. The enzyme is thought to decelerate cell aging [43].

When a genetically engineered derivative of the peroxisomal antioxidant enzyme catalase (CAT-SKL), induced by intracerebroventricular injection of $\mathrm{A} \beta_{25-35}$ in the mature rat brain, it is able to reduce the toxicity of the accumulated beta-amyloid in the brain [44]. Free radical mediated oxidative stress have long been considered to be involved in the pathogenesis of diabetic complications but could they also because protein aberrations and some pathology in cells [45]. Free radical using a catalase derivative reduce the pathology induced by amyloidosis toxicity in other cells, such as, pancreatic beta cells?

It should be noted that the CAT found in various foods, in its natural state, is largely broken down by pepsin during digestion but recent advances in the preparation of CAT have 
adapted its structure to be more biologically available, however, supplementation of new preparations of CAT may impact lifespan, altering the course of degenerative diseases and inhibiting the beta cell damage caused by oxidative stress. Experimental diets with diabetic models using rats, showed increases in antioxidant activity, including catalase and antioxidant protection of erythrocytes [46]. Individuals with a family history of T1DM receive prophylactic treatment with antioxidants, such as, SOD-2 and CAT that may reduce the occurrence of the condition.

Table 1. Demographics of the group of patients with diabetes and clinical diagnosis of complications

Demographics and diagnosis of patients with diabetes.

\begin{tabular}{|l|l|l|l|l|l|l|}
\hline Diagnosis & Normal & Diabetic & DC & DN & SD<20yrs & $\begin{array}{l}\text { No } \\
\text { complication } \\
\text { described }\end{array}$ \\
\hline $\begin{array}{l}\text { Number of } \\
\text { cases n=; } \\
\text { M:F }\end{array}$ & $\mathrm{n}=43 \mathrm{M}: 38 \mathrm{~F}$ & $\mathrm{n}=37 \mathrm{M}: 49 \mathrm{~F}$ & $\mathrm{n}=7 ; 4 \mathrm{M}: 3 \mathrm{~F}$ & $\mathrm{n}=16 ; 7 \mathrm{M}: 9 \mathrm{~F}$ & $\mathrm{n}=8 ; 5 \mathrm{M}: 3 \mathrm{~F}$ & $\mathrm{n}=55 ; 21 \mathrm{M}: 24 \mathrm{~F}$ \\
\hline $\begin{array}{l}\text { Age/years } \\
+ \text { SEM }\end{array}$ & NA & $19.3+1.43$ & $34.0+2.84$ & $47.3+5.54$ & $21.7+2.60$ & $26.7+1.13$ \\
\hline $\begin{array}{l}\text { Duration } \\
\text { of disease/ } \\
\text { years+SEM }\end{array}$ & NA & $20.9+1.22$ & $27.9+2.46$ & $30.8+2.94$ & $10.7+0.86$ & $18.4+1.30$ \\
\hline
\end{tabular}

Table 2: shows the percentage frequency of catalase genotypes for a diabetic population with and without complications.

\begin{tabular}{|l|l|l|}
\hline Diagnosis & Normal & Diabetic \\
\hline Number of cases n=; M:F & $\mathrm{n}=81 ; 43 \mathrm{M}: 38 \mathrm{~F}$ & $\mathrm{n}=86 ; 37 \mathrm{M}: 49 \mathrm{~F}$ \\
\hline Age/years \pm SEM & $\mathrm{NA}$ & $19.3+1.43$ \\
\hline Duration of disease/years+SEM & $\mathrm{NA}$ & $20.9+1.22$ \\
\hline $\mathrm{AA}$ & $0.0 \%(0)$ & $0.0 \%(0)$ \\
\hline $\mathrm{AB}$ & $2.5 \%(2)$ & $4.7 \%(4)$ \\
\hline $\mathrm{AC}$ & $4.9 \%(4)$ & $1.2 \%(1)$ \\
\hline $\mathrm{AD}$ & $1.2 \%(1)$ & $2.3 \%(2)$ \\
\hline $\mathrm{AE}$ & $0.0 \%(0)$ & $0.0 \%(0)$ \\
\hline $\mathrm{BB}$ & $2.5 \%(2)$ & $10.5 \%(9)$ \\
\hline $\mathrm{BC}$ & $9.9 \%(8)$ & $19.8 \%(17)$ \\
\hline $\mathrm{BD}$ & $14.8 \%(12)$ & $8.1 \%(7)$ \\
\hline $\mathrm{BE}$ & $2.5 \%(2)$ & $5.8 \%(5)$ \\
\hline $\mathrm{CC}$ & $16.0 \%(13)$ & $15.1 \%(13)$ \\
\hline $\mathrm{CD}$ & $27.2 \%(22)$ & $18.6 \%(16)$ \\
\hline $\mathrm{CE}$ & $6.2 \%(5)$ & $4.7 \%(4)$ \\
\hline $\mathrm{DD}$ & $4.9 \%(4)$ & $8.1 \%(7)$ \\
\hline $\mathrm{DE}$ & $4.9 \%(4)$ & $1.2 \%(1)$ \\
\hline $\mathrm{EE}$ & $2.5 \%(2)$ & $0.0 \%(0)$ \\
\hline $\mathrm{Si}$ & & \\
\hline
\end{tabular}

Significant differences reported between patients with diabetes and normal healthy controls. Patients with diabetes had a higher percentage of heterozygous copies ( $54 \%$; Chi-square $=5.87 ; \mathrm{p}=0.01$ ); normal controls had a higher homozygous percentage (63\%; Chi-square $=6.5$; $\mathrm{p}=0.01$ ).

No significant differences were observed between the groups (number of cases shown in parentheses)
Table 3 The frequency of alleles in the microsatellite region of the catalase gene in a population of diabetic patients with healthy controls. No significant differences were identified between these alleles.

\begin{tabular}{|l|l|l|}
\hline Alleles & Healthy Control & Diabetic \\
\hline $\mathrm{n}=$ & 162 & 172 \\
\hline A & $4.3 \%(7)$ & $4.1 \%(7)$ \\
\hline B & $17.3 \%(28)$ & $29.7 \%(51)$ \\
\hline C & $40.1 \%(65)$ & $37.2 \%(64)$ \\
\hline D & $29.0 \%(47)$ & $23.2 \%(40)$ \\
\hline E & $9.3 \%(15)$ & $5.8 \%(10)$ \\
\hline
\end{tabular}

\section{Acknowledgments}

A Houldsworth clinical scientist researcher, author, Hodgkinson clinical scientist supervisor and adviser, BA Millward, consultant endocrinologist, recruited patients, AG Demaine, project supervisor, funding and advisor.

\section{References}

1. World Health Organization, 2014. Global Health Estimates: Deaths by Cause, Age, Sex and Country, 2000-2012. Geneva, WHO.

2. Wilkin TJ. The accelerator hypothesis: a unifying explanation for type-1 and type-2 diabetes. Nestle Nutr Workshop serclin Perform Programme. 2006;11:139-150; discussion 150-3. Doi:10.1159/000094447.

3. Robertson RP, Harmon J, Tran PO. Poitout V. Beta-cell glucose toxicity, lipotoxicity, and chronic oxidative stress in type 2 diabetes. Diabetes. 2004;53Suppl 1:S119-24.

4. Jialal I, Devaraj S, Venugopal SK. Oxidative stress, inflammation, and diabetic vasculopathies: the role of alpha tocopherol therapy. Free Radic Res. 2002;36(12):1331-1336.

5. Devaraj S, Dasu MR, Jialal I. Diabetes is a proinflammatory state: a translational perspective. Expert Rev endocrinolmetab. 2010;1:5(1):19-28. Doi:10.1586/eem.09.44.

6. Cernea S, Dobreanu M. Diabetes and beta cell function: from mechanisms to evaluation and clinical implications. Biochem Med (Zagreb). 2013;23(3):266-280.

7. Kawahito S, Kitahata H, Oshita S. Problems associated with glucose toxicity: role of hyperglycemia-induced oxidative stress.World J Gastroenterol. 2009;15(33):4137-1442.

8. Del Guerra S, Lupi R, Marselli L, Masini M, Bugliani M, Sbrana S, et al. Functional and molecular defects of pancreatic islets in human type 2 diabetes. Diabetes. 2005;54(3):727-735.

9. Grundy SM. Pre-diabetes, metabolic syndrome, and cardiovascular risk. J Am collcardiol. 2012;59(7):635-643. Doi: 10.1016/j. jacc.2011.08.080.

10. Levinson W. Review of Medical Microbiology and Immunology (11th ed.). Mcgraw-Hill. 91-178. ISBN 978-0-07-174268-9.2010.

11. Bai J, Cederbaum AI. Mitochondrial CAT and oxidative injury. Biol. Signals Recept.2001;10: 189-199. DOI:10.1159/000046887.

12. Nilsson Goran E. Respiratory Physiology of Vertebrates. Cambridge: Cambridge University Press. ISBN 978-0-521-70302-4. 2010.

13. Imlay JA. Pathways of oxidative damage. Annual Review of Microbiology. 2003; 57:395-418. DOI: 10.1146/annurev. micro.57.030502.090938. 
14. Prescott LM, Harley JP, Klein DA. Microbiology (3rd ed.). Wm. C. Brown Publishers. Pp. 1996.

15. Halliwell B, Hu ML, Louie S, Duvall TR, Tarkington BK, Motchnik P,et al. Interaction of nitrogen dioxide with human plasma. Antioxidant depletion and oxidative damage. FEBS Lett.1992;313(1): 62-66.

16. Alfonso-Prieto M, Vidossich P, Rovira C. The reaction mechanisms of heme cats: an atomistic view by ab initio molecular dynamics. Arch biochembiophys. 2012;525(2):121-130. Doi:10.1016/j. abb.2012.04.004.

17.Alfonso-Prieto M, Biarnés X, Vidossich P, Rovira C. The molecular mechanism of the CAT reaction. J Am Chem Soc.2009;131(33):1175161. Doi: $10.1021 / j a 9018572$.

18. Góth L, Nagy T, Káplár M. Acatalasemia and type 2 diabetes mellitus. Orv Hetil.2015;156(10):393-398. Doi: 10.1556/OH.2015.30095.

19. Hakansson KO, Brugna M, Tasse L. The three-dimensional structure of CAT from Enterococcus faecalis. Actacrystallogr D biolcrystallogr. 2004;60(Pt 8): 1374-80.

20. Chelikani P, Fita I, Loewen PC. Diversity of structures and properties among cats. Cellular and Molecular Life Sciences CMLS. 2004;61(2):192-208. DOI: 10.1007/s00018-003-3206-5.

21. Hodgkinson AD, Bartlett, T, Oates PJ, Millward BA, Demaine AG. The response of antioxidant genes to hyperglycemia is abnormal in patients with type 1 diabetes and diabetic nephropathy. Diabetes.2003;52(3): 846-851.

22. Houldsworth A, Hodgkinson A, Millward BA, Demaine AG. SOD-2 antioxidant gene and diabetic complications.Gene. 2015;569(1):41-5. doi:10.1016/j.gene.2015.04.006.

23. Chistiakov D A, Turakulov RI, Shcherbacheva LN, Mamaeva GG, Galabolkin MI, Nosikov V V. Analysis of polymorphism of the D11S2008 locus of the CAT gene in patients with hypertension and ischemic heart disease in non-insulin-dependent diabetes mellitus in the Muscovite population. Genetika. 2000;36(3):423-426.

24. Chistiakov DA, Zotova EV, Savost'anov KV, Bursa TR, Galeev IV, Strokov IA, Nosikov VV. The 262T $>$ C promoter polymorphism of the catalase gene is associated with diabetic neuropathy in type 1 diabetic Russian patients. Diabetes Metab. 2006;32(1):63-68.

25.Zhengwen J, Akey JM, Shi J, Xiong MY, Wang Y,Shen X, et al . A polymorphism in the promoter region of CAT is associated with blood pressure levels, Human Genetics. 2001;109:95-98.

26. Nosikov VV. Genomics of type I diabetes mellitus and its late complications. MolBiol (Mosk). 2004;38(1):150-164.

26. Benjamini Y, Hochberg Y. Controlling the false discovery rate. A practical and powerful approach to multiple testing. J Roy Stat Soc. 1995;B 57(1):289-300.

28. Pask R, Cooper JD, Walker NM, Nutland S, Hutchings J, Dunger DB, et al. No evidence for a major effect of two common polymorphisms of the catalase gene in type 1 diabetes susceptibility. Diabetes Metab Res Rev. 2006;22(5):356-360.

29. Flekac M, Skrha J, Hilgertova J, Lacinova Z, Jarolimkova M. Gene polymorphisms of superoxide dismutases and CAT in diabetes mellitus. BMC Med Genet. 2008;9:30. doi:10.1186/1471-2350-9-30.

30.Sun, Y, Oberley LW, Elwell J, Sierra-Rivera E. Lowered antioxidant enzymes in spontaneously transformed embryonic mouse liver cells in culture. Carcinogenesis. 1993;14(7):1457-1463. doi:10.1093/ carcin/14.7.1457.

31.Van Wijk R, Van Wijk EP, Wiegant FA. Ives J. Free radicals and lowlevel photon emission in human pathogenesis: state of the art. Indian J Exp Biol. 2008;46(5):273-309.

32. Hull RL, Westermark GT, Westermark P, Kahn SE. Islet amyloid: a critical entity in the pathogenesis of type 2 diabetes. JClinEndocrinolMetab. 2004;89(8):3629-3643. DOI: 10.1210/jc.20040405 .

33. Westermark P, Andersson A, Westermark GT. Islet amyloid polypeptide, islet amyloid, and diabetes mellitus. Physiol Rev.2011;91(3):795-826. DOI: 10.1152/physrev.00042.2009.

34. Stefani M. Biological surfaces as catalysts of amyloid aggregate nucleation and primary sites of amyloid toxicity. Ital J Biochem. 2006;55(3-4):194-204.

35. Young AJ, Lowe GM. Antioxidant and prooxidant properties of carotenoids. Arch BiochemBiophys. 2001;385(1):20-27. DOI:10.1006/abbi.2000.2149.

36. Ye G, Metreveli NS, Donthi RV, Xia S, Xu M, Carlson EC, et al. CAT protects cardiomyocyte function in models of type 1 and type 2 diabetes. Diabetes. 2004;53(5):1336-1343.

37. Kawahito S, Kitahata H, Oshita S. Problems associated with glucose toxicity: role of hyperglycemia-induced oxidative stress. World J Gastroenterol. 2009;15(33):4137-4142. doi: 10.3748/wjg.15.4137.

38. Acharya JD, Ghaskadbi SS. Islets and their antioxidant defense. Islets. 2010;2(4): 225-235. doi: 10.4161/isl.2.4.12219.

39. Li YC, Korol AB, Fahima T, Nevo E. Microsatellites within genes: structure, function, and evolution. MolBiolEvol. 2004;21(6):9911007.

40. Barroso M, Gurnell VEF, Crowley M, Agostini JW, Schwabe MA, Soos GL, Maslen TDM, et al. Dominant negative mutations in human PPARbig gamma associated with severe insulin resistance, diabetes mellitus and hypertension. Nature. 1999;402:880-883. doi:10.1038/47254.

41. McCarthy MI, Abecasis GR, Cardon LR, Goldstein DB, Little J, Ioannidis JP, et al. Genome-wide association studies for complex traits: consensus, uncertainty and challenges. Nat Rev Genet. 2008;9(5):356369. doi: $10.1038 / \mathrm{nrg} 2344$.

42.Giordano CR, Terlecky LJ, Bollig-Fischer A, Walton, PA, Terlecky SR. Amyloid-beta neuroprotection mediated by a targeted antioxidant. Scientific Reports. 2014;4:4983. doi: 10.1038/srep04983.

43. Giordano CR, Terlecky SR. Peroxisomes, cell senescence, and rates of aging. BiochimBiophysActa.2012;1822(9):1358-1362. doi: 10.1016/j. bbadis.2012.03.013.

44. Nell HJ, Au JL, Giordano CR, Terlecky SR, Walton PA, Whitehead SN, et al.The targeted antioxidant, catalase-SKL, reduces beta-amyloid toxicity in the rat brain. Brain Pathol.2016. doi: 10.1111/bpa.12368.

45. Ramakrishna V, Jailkhani R. Evaluation of oxidative stress in Insulin Dependent Diabetes Mellitus (IDDM) patients. DiagnPathol. 2007;2:22. doi: 10.1186/1746-1596-2-22.

46. Vengerovski AL, Yakimova TV, Nasanova, ON. Influence of medicinal plants extracts on the functions and antioxidant protection of erythrocytes in rats with experimental diabetes mellitus. EkspKlinFarakol. 2016;79(2):29-33. 